\title{
Implementing Interdisciplinary \\ Curricula: Some Philosophical and Practical Remarks
}

\author{
CARL GOMBR I C H \\ University College London, 6 Gower Street, London WC1E 6BT, UK. \\ Email: c.gombrich@ucl.ac.uk
}

This paper looks in detail at the educational side of interdisciplinarity and recounts the philosophy and some practicalities of the implementation of University College London's successful Bachelor of Arts and Sciences (BASc) degree. In particular, we consider 'framing' and 'the ladder of abstraction' as notions that are useful in the philosophy of education. It is hoped that some of the ideas, challenges and successes described here will be helpful to others wishing to implement interdisciplinary curricula in their own institutions.

The interest in creating better conditions for interdisciplinarity within higher education has been a running theme for much of the last century in many Western universities. $^{1-3}$ The focus - as with discussion of universities in general - is often on questions to do with research: how can we foster better interdisciplinary research to deal with complex, real-world problems such as climate change or transport? How can we ensure that structures are in place to evaluate and reward good interdisciplinary research? And so on. But even within publications that focus on the research side, there is often a section dedicated to how undergraduates might better be educated in interdisciplinary ways. The interest here is in providing an interdisciplinary education that might both prepare graduates better for interdisciplinary research careers and which is more applicable to the vast majority of undergraduates - be of more relevance to careers outside of university than an education in just one discipline. ${ }^{4,5}$

\section{A Little More on the Motivations for Implementing an Interdisciplinary Curriculum}

From a purely educational point of view, it would seem odd to confine an education solely to one discipline. Indeed, in the Western tradition, for much of the last 1000 years, to be educated has meant having a wide range of knowledge, interests and 
abilities. This was the ambition of the Liberal Arts curriculum in European Universities, from the foundation of Bologna in 1088 until roughly 1800, the aim of Humboldt's Bildung in Germany in the nineteenth century, and the goal of the Anglophone revival of the liberal arts in the US in the eighteenth to nineteenth century, which continues to the present day. The concern to 'specialize' is a relatively modern worry that can be traced to Adam Smith's ideas about specialization in an industrial workforce, the rise of scientific disciplines and sub-disciplines from the seventeenth century onwards and the increase in the sheer number of people who have achieved a high level of education over the last 200 years or so. ${ }^{6}$

There is an inherent intellectual interest, then, in offering a broad curriculum - one that aligns with the highest ideals of being educated. But 'broad' can mean several things in this context, and we must pause for a moment to consider the differences between 'liberal arts', 'liberal arts and sciences' and 'interdisciplinary' as adjectives that might apply to such an undergraduate education.

'Liberal arts' is the English translation of the Latin artes liberales, which, as noted above, was the dominant conception of the university curriculum for hundreds of years in Europe. This curriculum - usually parsed as the Trivium of grammar, rhetoric and logic, plus the Quadrivium of arithmetic, astronomy, music and geometry - always contained both what we would call arts and sciences - although these disciplinary distinctions did not then exist in the modern way. However, liberal arts, in some contemporary literature, has come to mean an agglomeration of what we now call humanities and non-quantitative social sciences, and the 'liberal arts curriculum' in this guise is defended by arguing for the value of this group of disciplines. ${ }^{7}$ In my view, although this defence is understandable and often necessary (given the frequent misguided attacks on these disciplines and the threat they are under due to a withdrawal of funds for research and teaching), ${ }^{8}$ to do so under the banner of 'liberal arts' is something of a conceptual mistake. In fact, the moniker 'liberal arts and sciences' better reflects in contemporary language the heritage of the historic curriculum as well as its contemporary ambitions. What both these conceptions of the curriculum share, however, is the idea that education should be broader than a single (or perhaps even a couple of) discipline(s). This view of higher education they also share with the concept of an interdisciplinary education. However, interdisciplinary education, as distinct from either liberal arts or liberal arts and sciences, requires, in addition, some attempt to find a relationship between the disciplines, usually (but not exclusively) in the form of an explicit integration or synthesis of one or more disciplines. ${ }^{9,10}$

Interdisciplinary education, then, is part of the great tradition of liberal arts education, but it should contain both arts and sciences and, in addition, look for syntheses and integration across the disciplines. This is the purist educational argument for an interdisciplinary education. However, there are also other more instrumentalist arguments which apply in the twenty-first century.

Since this article is concerned primarily with the implementation of such a curriculum, rather than a detailed background, we briefly mention here just three other arguments which support an interdisciplinary curriculum. 
(1) Contemporary graduate work is increasingly poorly aligned with single discipline study. The Association of Graduate Recruiters report from 2016 shows that $82 \%$ of graduate jobs in the UK are now degree agnostic. ${ }^{11}$ That is, a degree in any discipline is considered sufficient for $82 \%$ of graduate jobs and no particular discipline is necessary for these jobs (although some university degree is still required). This is a striking statistic, but it stands to reason when we consider that, in the UK at least, around $80 \%$ of jobs are in the service sector. ${ }^{12}$ That percentage figure is fast rising in all growing economies. Service jobs that are not directly related to traditional trades or manual labour naturally require more breadth, more knowledge 'across the piece' and more soft skills - things that are not well aligned with any particular discipline. ${ }^{6}$ An interdisciplinary education is therefore at least as likely to be helpful for a graduate career in around $80 \%$ of graduate jobs as a degree in any particular discipline.

(2) The internet is revolutionizing the way we learn. It is forcing us to rethink our architecture of knowledge, ${ }^{13}$ what we can assume as foundational knowledge, ${ }^{14}$ what it is worthwhile to learn (due to the rise of AI and robotics), ${ }^{15}$ a host of issues around 'post-truth', media fabrication and incompetence, and, soon, our response to breathtaking illusions created by virtual and augmented reality. The way the internet is structured as a network is, in fact, closer to the architecture of our brains than a traditional library cataloguing system or knowledge categories defined by university departments. We might therefore be optimistic that the ubiquity of the internet will lead to a great age for learning. The breakdown of old structures and the establishing of new and looser networks mean that it will be challenging indeed to decide how this learning might best be institutionalized. However, some kind of interdisciplinary education is a better fit for this new architecture than an existing siloed or monodisciplinary one.

(3) Academic researchers in many key areas will require interdisciplinary training. The so-called 'complex, real-world problems' ${ }^{16}$ of, for example, sustainability, climate change, human-computer interaction, health, transport, fin tech, etc., are manifestly not able to be solved by a single disciplinary approach. It is true that a researcher can always train in a single discipline and then 'transfer over' to become an interdisciplinary researcher later in their career - and, indeed, some eminent academics of the previous generation have advised this. ${ }^{3}$ But I am more optimistic. There is growing evidence that there are other ways to get the right sort of training and that earlier exposure to interdisciplinarity may serve such researchers better in the longer run. We are now seeing students with interdisciplinary undergraduate 
degrees progress well, and in some cases in an accelerated fashion, to interdisciplinary PhDs. ${ }^{17}$

\section{Implementation - First Steps}

This, then, is the historic, socio-political and personal background (if we can consider education to be a personal enterprise), providing a rationale for establishing an interdisciplinary programme in the twenty-first century. There is still the question of how to implement it successfully. In what follows, we consider the Arts and Sciences BASc at University College London (UCL) as a case study of successful implementation.

There are good indicators that the implementation of the interdisciplinary Arts and Sciences BASc at UCL has indeed been successful. The degree now enrols 120 students per year by competitive application and has $\sim 450$ students on the programme in total, including international affiliates who join for one term or one year. The degree classifications are very strong (helped by outstanding capstone dissertations by many students); students achieve excellent grades in single disciplines, alongside their more interdisciplinary work; the degree has, twice in succession, been in the top $10 \%$ of degrees at UCL for student satisfaction; the student retention rates are the highest in the faculty where the degree is housed; students progress to a wide range of postgraduate master's and $\mathrm{PhD}$ options at world-leading universities; and, in employment, our rate of 'graduate employment' is considerably above the UCL average. There are approximately five applicants for every place and the number of applications has been growing at roughly 15\% per annum since the first round of applications in 2011.

However, when the idea for the degree was first floated, around 2008-2009, the first steps towards its development were really something of an experiment and involved a considerable amount of risk and many unknowns. The original idea was a joint one, due to the then-Provost, Professor Sir Malcolm Grant, and Vice Provost, Professor Michael Worton. ${ }^{18}$ The degree featured prominently in the Education Strategy of the period. ${ }^{19}$ Sir Malcom's vision was for a classical liberal arts course in which students could take multiple electives and would therefore encounter new disciplines and perspectives. Professor Worton's view was of a more radical interdisciplinary programme, intent on problematizing some of the assumed boundaries between, say, medicine and the humanities, or quantitative and qualitative methods. The current author was appointed in 2010 to lead the development and launch of the degree in 2012, and initially struggled with these rather different visions. In fact, however, it soon became clear that once the curriculum is opened up to be more liberal, the interdisciplinarity can happen naturally, if required. Development of the curriculum began in earnest in 2010 with my appointment, and a Steering Committee for the degree was constituted which, at its peak in 2011, comprised more than 20 members, including academics from all levels of management, all faculties, and colleagues from registry, IT, estates and careers. This stakeholder engagement across 
the entire institution and leadership from the very top was crucial in laying good foundations for the degree and in giving it sufficient momentum to help overcome any up-coming challenges.

The entire project of creating and developing the curriculum, as well as the institutional implementation, was close to what is called 'action research' (sometimes called 'learning by doing'), although this is really over-theorizing the process and imputing to it, post-hoc, a theoretical methodology that was not strongly present at the time. In fact, the process was more entrepreneurial and iterative and did not involve the sort of detailed design process one might associate with a complex engineering project, such as designing a racing car or a sustainable energy system. Of course, there was a great deal of careful thought put into the structure and implementation of the curriculum by numerous colleagues over two years. Nevertheless, the theoretical underpinnings for the programme, and also the understanding and explanation of its success, have emerged more completely as the programme has developed and become established.

To be closer to the spirit of the project and the chronology, therefore (and, indeed, to be true to the notion of action research, one outcome of which is to 'produce guidelines for best practice' - Wikipedia), in what follows we first present the curriculum and then the philosophy as it emerged to provide greater coherence and an explanation for its success. ${ }^{20}$

\section{The Arts and Sciences BASc Curriculum}

The curriculum shares some commonality with related curricula in liberal arts institutions in the US and elsewhere but has some defining characteristics.

Study time for each student is spent $50 \%$ on the Core of the degree and $50 \%$ on what are called Pathways. The Core is where the more radical inter-, post- and

Table 1. Core modules on the Arts and Sciences BASc.

CORE

\begin{tabular}{|c|c|}
\hline Compulsory Core modules & Interdisciplinary Electives (selected) \\
\hline $\begin{array}{l}\text { Approaches to Knowledge: An Introduction to } \\
\text { Interdisciplinarity; } \\
\text { Exploring Complexity: Quantitative Methods; } \\
\text { Interdisciplinary Research Methods; } \\
\text { The Knowledge Economy (a 'real-world' consultancy } \\
\text { project, in the final year of the degree, on which all } \\
\text { students work in small teams to assist a local business); } \\
\text { Final year (capstone) interdisciplinary dissertation; } \\
\text { Foreign language (students choose their own language to } \\
\text { study). }\end{array}$ & $\begin{array}{l}\text { Data Visualization } \\
\text { Evolution and the Human } \\
\text { Condition } \\
\text { Qualitative Thinking } \\
\text { Technology, Heritage and } \\
\text { Material Culture } \\
\text { Migration and Health } \\
\text { Object-based Learning: } \\
\text { Museum Stories } \\
\text { Psychology and the Real } \\
\text { World } \\
\text { Understanding Cities } \\
\text { Environmental Sociology }\end{array}$ \\
\hline
\end{tabular}


Table 2. The Arts and Sciences BASc Pathways.

\begin{tabular}{|c|c|c|c|}
\hline \multicolumn{4}{|c|}{ The Pathways } \\
\hline Cultures & Societies & $\begin{array}{l}\text { Health and } \\
\text { Environment }\end{array}$ & Sciences and Engineering \\
\hline Anthropology & Archaeology & $\begin{array}{l}\text { Anthropology } \\
\text { (Biological) }\end{array}$ & Chemistry \\
\hline Art History & Geography & Biochemistry & Computer Science \\
\hline Design & History & Biomedicine & Earth Sciences \\
\hline English & $\begin{array}{l}\text { International } \\
\text { Relations }\end{array}$ & Ecology & Economics \\
\hline Film & Law & Environmental Sciences & Engineering \\
\hline History & Philosophy & Life Sciences & Mathematics \\
\hline Languages & Political Economy & Pharmacology & Physics \\
\hline Literatures & Politics & Psychology & $\begin{array}{l}\text { Science and Technology } \\
\text { Studies }\end{array}$ \\
\hline Philosophy & Sociology & Neuroscience & Statistics \\
\hline
\end{tabular}

non-disciplinary modules are housed and the Pathways are selections of broadly cognate, more standard academic disciplines (see Tables 1 and 2 - tables from British Academy Report ${ }^{3}$ ).

Each student 'majors' in one Pathway and 'minors' in another, with the requirement that if your major is a science major (Health and Environment or Sciences and Engineering) then your minor must be a non-science Pathway (Cultures or Societies), and vice versa.

As part of the Core, all students must study a modern foreign language. There is also full support for an internship before the final year of study and students may choose to extend the degree to four years by spending the third year abroad at a partner university.

The timetable for an individual student below (Figure 1) makes clearer the structure of the course from the student's perspective.

The timetable shows each year divided into eight, half-course units (the ' 0.5 ' in the second row, which is equivalent to 7.5 ECTS). Since the choice of Dissertation and the Foreign Language are personal to the student, the only fully compulsory modules for all Arts and Sciences students are in fact:

- Approaches to Knowledge: An Introduction to Interdisciplinarity;

- Quantitative Methods;

- Interdisciplinary Research Methods;

- Knowledge Economy.

Finally, it is worth noting that the creation and delivery of new modules in the Core allow for the introduction of many innovative forms of teaching and assessment, such as flipped lectures, student-led conferences, team-made podcasts, vlogs, 
Timetable Structure for BASc

\begin{tabular}{|c|c|c|c|c|c|c|c|c|}
\hline \multicolumn{5}{|c|}{ CORE } & \multicolumn{4}{|c|}{ PATHWAY } \\
\hline & 0.5 & 0.5 & 0.5 & 0.5 & 0.5 & 0.5 & 0.5 & 0.5 \\
\hline $\begin{array}{l}\text { Final } \\
\text { Year }\end{array}$ & $\begin{array}{l}\text { Knowledge } \\
\text { Economy }\end{array}$ & Dissertation & Dissertation & Lang. & Maj & Maj & Maj & Min \\
\hline \multicolumn{9}{|c|}{$\begin{array}{l}\text { Work Placement } \\
\text { Year Abroad (on 4-year Programme) }\end{array}$} \\
\hline $\begin{array}{l}\text { Year } \\
2\end{array}$ & $\begin{array}{l}\text { Object- } \\
\text { based } \\
\text { learning OR } \\
\text { Qualitative } \\
\text { Thinking OR } \\
\text { Quantitative } \\
\text { Methods II }\end{array}$ & $\begin{array}{l}\text { Interdisciplinary } \\
\text { Electives }\end{array}$ & $\begin{array}{l}\text { Maj or Min } \\
\text { option }\end{array}$ & Lang. & Maj & Maj & Maj & Min \\
\hline $\begin{array}{c}\text { Year } \\
1\end{array}$ & $\begin{array}{l}\text { Approaches } \\
\text { to } \\
\text { Knowledge }\end{array}$ & $\begin{array}{l}\text { Interdisciplinary } \\
\text { Methods }\end{array}$ & $\begin{array}{l}\text { Quantitative } \\
\text { Methods }\end{array}$ & Lang. & Maj & Maj & Maj & Min \\
\hline
\end{tabular}

Figure 1. Arts and Sciences BASc, student timetable.

presentations, blogs, research proposals, reports for external organizations, and so on.

\section{Framing and the Ladder of Abstraction}

We now turn our attention to aspects of educational philosophy that underpin the curriculum and consider two ways in which the concept of framing has helped with its successful implementation:

(1) Framing the worth and importance of the programme as a whole;

(2) Providing frames for each individual student to best construct their own interdisciplinary programme.

Of course, the two are connected as without multiple successful individual student experiences it would be difficult to frame the overall programme positively. Nevertheless, these ideas are distinct, as is shown below.

What are frames and what is framing? As George Lakoff writes, 'frames are mental structures that shape the way we see the world. ${ }^{21}$ They are part of the cognitive unconscious of each of us, 'structures in our brains that we cannot consciously access but know by their consequences [i.e. the affect these structures have on our assumptions and actions]. "Common sense" is made up of ... automatic ... inferences that follow from our unconscious frames' (Ref. 21, p. xii). Lakoff most often applies the idea of framing in the realms of politics and economics, but it applies no less in education and other 
social sciences. In devising, designing, implementing and promoting a radical interdisciplinary programme, it is not surprising that framing is immensely important. Indeed, almost by definition, any programme in any sphere which is 'radical' is outside the normal frames used in the sphere in which it is implemented. In order to shift the frames associated with education, one must shift the frames though which all stakeholders (students, teachers, employers, etc.) see education itself.

In fact, we have already done some of the framing for the overall programme above, when we listed three reasons an institution may think it worthwhile to set up an interdisciplinary degree today. For example, when students, parents and other academic colleagues become aware that such a curriculum is actually a return to a great historic tradition, the more conservative among them may support the change. The frame shift here is simply from, 'this is a radical new type of education' to 'this is actually quite traditional'! On the other hand, stakeholders who are more concerned with and aware of the changing nature of work are more likely to support an educational venture such as this if it is made clear that it prepares students better for the twenty-first century graduate jobs market.

However, only giving reasons and facts may still not persuade. ${ }^{22}$ Prejudices and notions of what is good or worthwhile die hard. A re-purposing of language is therefore often key.

To see what this might mean, consider the term 'monodisciplinary', which you may have noticed used above to describe a conventional single honours programme. Use of this term flips the usual perception:

$($ single discipline $=$ specialism $=$ good $) \rightarrow($ interdisciplinary degree $=$ fuzzy $/$ vague $=$ bad $)$

to:

( monodisciplinary degree $=$ only a part of an interdisciplinary degree $=$ inferior $)$

$\rightarrow$ (interdisciplinary degree $=$ more complete $/$ fuller $=$ superior $)$.

In other words, using the term 'monodisciplinary' puts single disciplinary degrees in the same category as interdisciplinary degrees but then shows them to come up second best by comparison.

We might note another reframing that occurs when discussing the metaphors we use to describe the structure and categorization of knowledge itself. Perceptions about this structure affect, of course, how we think it best to engage with knowledge in educational programmes. Is knowledge really some kind of tree - as Aristotle and the medievalists thought - with a well-defined central body in the form of a trunk and increasingly peripheral branches of knowledge? Or is it more like a network, a rhizome, as Deleuze and Guattari, ${ }^{23}$ Manuel de Lima $^{24}$ and others have more recently argued, with many separate 'nodes' of information, concepts and methods, and various 'edges' made of people, histories, books and ideas connecting these nodes? The latter is surely closer to how we now encounter and interact with knowledge on the internet. If the case for knowledge as a network has some merit, then the frame for a curriculum shift from one that is siloed and made of wooden, 
inflexible tree-like structures, to one that is more flexible, resilient, yet more loosely joined and connected in network-style, has considerable appeal.

As Lakoff has argued persuasively, this is not about spin. Quite the contrary. It is about revealing truths that have hitherto been concealed by tradition, prejudice or simply by different values. Values are central here. This is not the place to go into a philosophical discussion of values, but we can note that, to some extent, values are not amenable to logic. However, changing values is possible through appeal to emotion and, indeed, by re-framing the discussion. For example, as Roman Krznaric has shown, the different values attached to slavery were shifted dramatically by reframing the debate through appeals to empathy - then a new concept. ${ }^{25}$ In our example of education, the use of the word 'monodisciplinary' indicates that we think single disciplinary study is too narrow, we value a broader education as a good in itself as well as for instrumental reasons. Our use of this new word reframes the value of different types of education and allows us to build a case.

So much for the large-scale, macro framing of the course, what about the individual frames for each student? How is it possible for students to achieve breadth and depth, and excellent graduate outcomes?

So far, we have only qualitative studies in the form of extended student interviews and student feedback to support any speculation in this regard. ${ }^{26}$ However, building on this research, it seems reasonable to suggest that the three compulsory first-year Core courses, as they are common to all students, play an important role in the success of the programme. Our view is that these modules frame the programme in such a way as to provide intellectual, cognitive and moral support, thus relieving some of the cognitive bandwidth load associated with trying to span many disciplines or espouse too many different intellectual positions.

The frames provided by these three Core courses are constructed by working at both ends of what Cartwright and Hardie, in the context of social sciences, call the 'ladder of abstraction. ${ }^{27}$ In this case, Approaches to Knowledge is towards the upper end of the ladder, and the two methods courses towards the lower. As I have explained elsewhere:

'Approaches to Knowledge' is a conceptual course. It asks students to take a 'high-level' view of the disciplines from different epistemological and ontological perspectives. The course has lectures and assessments on such things as 'Truth and the Disciplines', 'Evidence and the Disciplines' and 'Imperialism and the Disciplining of Knowledge'. The other two core courses - a quantitative methods course and a mixed (interdisciplinary) methods course - are more 'ground-level'. They give students immediate tools with which to carry out their own research. Students learn methodological techniques in, for example, coding, statistics, survey design and interviewing protocols, and generate their own projects as part of assessments in which they practise these techniques.

It is important to get this balance [across the ladder of abstraction] right. Too little abstraction and few students will be able to rise above the parochial concerns of any particular discipline, to see a picture of wider import and meaning; too much abstraction and students will feel disconnected from practical realities, bothered by a feeling of irrelevance and distance from things which affect their lives and the lives of others. To effect this balance, 'Approaches to Knowledge' abstracts to a higher level 
[discussion of] disciplinary differences and contingencies, whereas the two methods courses are less concerned with [such a discussion] but ask students to use tools on problems which are amenable to these tools. ${ }^{28}$

By its very nature, the ontology of any given discipline is fairly well defined. It has a history, founding fathers (and, all-too-slowly, the recognition of founding mothers), established methods, leading journals and (usually) a well-bounded object of study. In introductory classes this disciplinary identity is frequently summarized in a strapline or mission statement: 'Economics is a science which studies human behaviour as a relationship between ends and scarce means which have alternative uses'; 'Physics is the study of the physical universe at all scales', 'Anthropology is the study of humans through their societies and cultures', and so on. A student studying economics can call themselves 'an economist', likewise a physics student, 'a physicist'. But an interdisciplinary student can be severely challenged by this disciplinary essentialism. What are you? is a question that can be troubling for a 19-year old student to answer. But by providing a different frame, a conceptual frame in which disciplines are situated as more contingent and interrelated objects, and a frame in which tools are given to the student to make their own connections across and between disciplines and to begin their own research, the student need no longer be troubled by what they 'are' but instead may concentrate on what they $d o$. They can focus simply on what they are interested in and which problems they would like to engage with, rather than worrying about which discipline they belong to. This approach to learning brings them in line with no less a figure than Karl Popper: 'We are not students of some subject matter, but students of problems. And problems may cut right across the borders of any subject matter or discipline. 29

Thus, on the Arts and Sciences BASc we have students interested in global child mental health, studying this from psychological, sociological, geographical and medical perspectives; students studying anaerobic digestion in the circular economy from economic, engineering, legal and sociological perspectives, and so on. The frames given to them through the Core courses provide them with the intellectual tools and confidence to create and pursue such hybrid identities.

\section{Final Year and One More 'Summing-up' Frame}

In the final year of the programme, all students do a personal dissertation and undertake a team project - as part of the Knowledge Economy module - providing consultancy services and writing a report for a local external organization.

The dissertation must be explicitly interdisciplinary and the grading rubric is based on the work of Veronica Boix Mansilla and others at the Harvard Graduate School of Education. ${ }^{30}$ There are frequent challenges in explaining this rubric to staff who are less familiar with interdisciplinarity, and we can certainly do more to clarify our intentions. ${ }^{31}$ Nevertheless, the results produced by students in their dissertations are often outstanding and highly commended by our external examiners.

In the consultancy project, the partner organization is usually a charity or social enterprise but we also include some small and medium for-profits as many students 
are interested in the workings of these organizations. In the given 'neo-liberal' climate, there is much interest in how universities can better serve their local communities and wider society ${ }^{4}$ and this module provides a good example, as well as helping with students' graduate employability.

The two final-year assessments of the individual dissertation and team-written consultancy report, together frame the benefits of interdisciplinary undergraduate education: the intellectual aspects and employability aspects, and provide a kind of summation from the students' perspective.

\section{What are Some of the Challenges of Implementation?}

The challenges of providing the conceptual basis for the structure and content of the curriculum have been significant, but they have not been insurmountable. We have outlined above some of the philosophy that now sits alongside the socio-historicopolitical reasons to provide support for such a programme.

There has also been the less significant challenge of what interdisciplinary electives to include as options, alongside the compulsory Core - but this has been fun! 'Technology, Heritage and Material Culture', seems a natural choice, as does 'Interdisciplinary Game Theory', taught by an academic with a background in classics and economics, but is there such a thing as 'interdisciplinary art'? And how interdisciplinary can a course in psychology be? Much interesting debate is had amongst faculty on these matters but consensus is usually found. There are also some issues of prerequisites and progression to consider for students studying a broad range of disciplines. At UCL, this has, perhaps surprisingly, been only a minor problem, and students have generally achieved very good grades in more advanced modules in disciplines as varied as organic chemistry, engineering, art history and politics, whilst taking an interdisciplinary suite of subjects much wider than single honours students.

Less intellectually interesting but far more significant are the challenges of implementation due to bureaucratic infrastructures. Most universities, in the UK and large parts of Europe at least, are ruled by departments. The well-known witticisms that a university is a 'series of individual faculty entrepreneurs held together by a common grievance over parking' or 'the real world has problems, universities have departments' capture this structure and dynamic and are felt all-too-keenly by students trying to negotiate these siloed and well-defended departmental spaces.

Departments generally have little incentive to look after students other than their own. For interdisciplinary students there are thus access to module issues, timetabling issues, student support issues and many other issues that come from being a hybrid beast in a stable of mono-cultural animals. Mitigating these difficulties can require many hundreds of hours from dedicated staff.

At UCL there are recent moves to create a centralized module-selection tool that will enable students to have more control over their student diets and not be overly constrained by departmental requirements. The early signs are positive, but it is yet to be seen how much departmental pushback there will be and how much rigidity and 
'locking out' of non-departmental students from departmental modules will be built in to the system.

There is to my mind no doubt that the establishing and administering of such a programme is easier if there is direct and substantial support from senior figures at the centre of the organization and if processes such as admissions, timetabling and module selection are built from the outset with interdisciplinary students in mind. As discussed above, this contemporary, looser, networked structure to a curriculum is challenging to institutionalize but it is vital that universities think more along these lines if they are to respond to current changes in our interaction with knowledge and to continue to lead in teaching and research.

\section{Conclusion}

This article has offered some thoughts on the socio-historical and philosophical rationales for implementing an interdisciplinary undergraduate curriculum. Two concepts - those of framing and the ladder of abstraction - have been explored as ideas that may support such an interdisciplinary enterprise. Some challenges of implementation have been outlined, but these are argued to be more bureaucratic and institutional, rather than conceptual or related to learning, or, indeed, to successful graduate outcomes.

There is more to do. We are starting to explore the metacognitive benefits of interdisciplinary education in such areas as: openness, creativity, bridging and perspective-taking. ${ }^{24}$ If such benefits are found to be widespread and in line with what many stakeholders are arguing are necessary attributes for the next generation of graduates, ${ }^{32}$ then there will be further support for interdisciplinary programmes.

One final word. This is not to say that all university programmes should be interdisciplinary. There will always be a substantial place for disciplinary scholarship and specialization. But in the current system the number of interdisciplinary courses is very small: there is room for growth and it is hoped that some of the ideas offered here may assist future implementations to be successful.

\section{Notes and References}

1. J. Cohen-Cole (2014) The Open Mind (London: University of Chicago Press).

2. A. Repko (2012) Interdisciplinary Research (London: Sage Publications).

3. https://www.britac.ac.uk/blog/crossing-paths- $\%$ E2\%80\%93-british-academyreport-interdisciplinarity-uk-universities.

4. https://www.leru.org/files/Interdisciplinarity-and-the-21st-Century-ResearchIntensive-University-Full-paper.pdf.

5. https://www.heacademy.ac.uk/knowledge-hub/interdisciplinary-provisionhigher-education-current-and-future-challenges.

6. C. Gombrich (2016) Polymathy, generalism and the future of work: a little theory and some practice from UCL's Arts and Sciences Degree. Experiences in Liberal Arts and Science Education from America, Europe, and Asia 2016 (New York: Palgrave Macmillan), pp. 75-89.

7. M. Nussbaum (2010) Not for Profit (Oxford: Princeton University Press). 
8. https://www.theguardian.com/education/2018/feb/18/cutting-tuition-fees-wouldbackfire-justine-greening-warns-theresa-may.

9. J. Klein (1990) Interdisciplinarity: History, Theory and Practice (Michigan: Wayne State University Press).

10. V. Boix Mansilla (2007) Targeted Assessment of Students' Interdisciplinary Work: An Empirically Grounded Framework Proposed https://www.is.ucf.edu/docs/ Mansilla_Duraising_2007_Targeted $\% 20$ Assessment $\% 20$ of $\% 20$ Students $\%$ E2 $\%$ $80 \% 99 \% 20$ Interdisciplinary $\% 20$ Work $\% 20$ An $\% 20$ Empirically $\% 20$ Grounded $\%$ 20Framework $\% 20$ Proposed.pdf.

11. https://www.justoncampus.co.uk/wp-content/uploads/2016-AGR-Annual-Survey2.pdf.

12. https://visual.ons.gov.uk/five-facts-about-the-uk-service-sector/.

13. P. Morville (2014) Intertwingled: Information Changes Everything (Michigan: Semantic Studios).

14. D. Weinberger (2011) Too Big To Know (New York: Basic Books).

15. A. McAfee and E Brynjolfsson (2014) The Second Machine Age (London: W.W. Norton).

16. http://quaestio.blogweb.casa.ucl.ac.uk/real-challenges/.

17. Three graduates from the BASc have now progressed to PhDs since the first graduating class of 2015. Two of them, unusually, have progressed directly - i.e. without taking a master's programme - to interdisciplinary PhDs from their undergraduate studies: one in computational, cognitive neuroscience and one in artificial intelligence and energy consumption.

18. https://www.ucl.ac.uk/white-paper/provost-white-paper.pdf.

19. L. De Greef, G. Post, C. Vink and L. Wenting (2017) Designing Interdisciplinary Education (Amsterdam: Amsterdam University Press).

20. Since the launch of the BASc there have been more excellent, practice-based books on interdisciplinary education, such as L. De Greef, G. Post, C. Vink and L. Wenting (2017) Designing Interdisciplinary Education (Amsterdam: Amsterdam University Press) and we continue to benefit from these and other works.

21. G. Lakoff (2014) Don't Think of an Elephant! (Vermont: Chelsea Green Publishing), p. xi.

22. https://www.newyorker.com/magazine/2017/02/27/why-facts-dont-change-ourminds.

23. G. Deleuze and F. Guattari (1987) A Thousand Plateaus: Capitalism and Schizophrenia (London: The Athlone Press).

24. https://www.youtube.com/watch?v=nJmGrNdJ5Gw.

25. file:///C:/Users/carl/Downloads/empathy_education_web.pdf.

26. C. Gombrich and M. Hogan (2016) Interdisciplinarity and the student voice. In: R. Frodeman, (Ed.) The Oxford Handbook of Interdisciplinarity, 2nd edn (Oxford: Oxford University Press).

27. N. Cartwright and J. Hardie (2012) Evidence-based Policy: A Practical Guide to Doing It Better (Oxford: Oxford University Press).

28. C. Gombrich (2017) Integrating sciences and engineering in the liberal arts curriculum. In: M. Peters (Ed.), Encyclopedia of Educational Philosophy and Theory (Singapore: Springer).

29. K. Popper (1965) Conjectures and Refutations (London: Routledge, Kegan and Paul), p. 67.

30. https://oakland.edu/Assets/upload/docs/AIS/Boix-Mansilla-Rubric.pdf. 
31. L. Rutting, G. Post, M. De Roo, S. Blad and L. De Greef (2016) An Introduction to Interdisciplinary Research: Theory and Practice, edited by S. Menken and M. Keestra (Amsterdam: Amsterdam University Press).

32. http://www.oecd.org/education/2030/oecd-education-2030-position-paper.pdf.

\begin{abstract}
About the Author
Carl Gombrich is the Programme Director of the interdisciplinary Bachelor of Arts and Sciences (BASc) degree at University College London. He has led the programme through its development and launch in 2012. Carl has a background in maths, physics, philosophy and music. He writes and speaks regularly on interdisciplinary education, liberal arts and sciences and the future of higher education and its relation to work. He is a Principal Fellow of the Higher Education Academy and sat on the British Academy Working Group on Interdisciplinarity.
\end{abstract}

